Check for updates

Cite this: Chem. Sci., 2018, 9, 7986

( All publication charges for this article have been paid for by the Royal Society of Chemistry

\title{
Reversible on-off switching of both spin crossover and single-molecule magnet behaviours via a crystal-to-crystal transformation $\dagger$
}

\author{
Dong Shao, (D) a Le Shi, (D) a Lei Yin, ${ }^{b}$ Bao-Lin Wang, ${ }^{c}$ Zhen-Xing Wang, (D) *b \\ Yi-Quan Zhang (iD) *c and Xin-Yi Wang (ID *a
}

\begin{abstract}
The on-off switching of spin-crossover (SCO) and single-molecule magnetism (SMM) remains highly attractive, especially if it involves dynamic crystal-to-crystal transformation. Herein we report the first molecule, a mononuclear cobalt(I) complex, that exhibits on-off switching between SCO and SMM reversibly during crystal-to-crystal transformation. Subtle structural transformation triggered by a simple dehydration-rehydration process induces significant geometrical changes of the Coll center and modification of the supramolecular interactions and switches its colour and magnetic properties (dark $\mathrm{red} / \mathrm{SCO}$-on/SMM-off $\leftrightarrow$ orange/SCO-off/SMM-on). This work suggests that modification of the weak supramolecular interactions could be very effective in achieving switchable materials involving both SCO and SMM properties.
\end{abstract}

Received 24th June 2018

DOI: $10.1039 /$ c8sc02774a

rsc.li/chemical-science

materials have been intensively pursued as magnetically bistable materials. In principle, the magnetic bistability of the SCO complex is related to the ligand field strength of the metal center, while that of the SMM complex mainly depends on the magnetic anisotropy. As the ligand field strength of the metal center is very sensitive to external stimuli, dynamic spin state switching in SCO materials has been vigorously investigated, leading to a myriad of SCO complexes showing various tunable properties. Among them, only a few examples occurred in the SC-SC fashion. ${ }^{7,8}$ In contrast, since it is very difficult to dynamically tune the magnetic anisotropy of the metal center, few dynamic SMM materials with switchable properties, especially complete on-off switching, have been documented. ${ }^{11,12,17}$

As the saying "you can't have your cake and eat it" states, SMM and SCO properties are usually inimical to each other. For SMM materials, highly anisotropic spin quantum numbers are of paramount importance, which are unfortunately not favoured for SCO complexes because they normally show an isotropic low spin state ( $S=0$ or $1 / 2)$ at low temperatures. Therefore, despite the vast number of SCO and SMM materials reported to date, ${ }^{20-22}$ compounds exhibiting both bistabilities are very limited. ${ }^{23-29}$ To achieve the high spin (HS) state preferred for SMM materials, light irradiation to the metastable HS state and partial SCO with HS fractions trapped at low temperature are two successful strategies, leading to several interesting photo-switchable SMM materials. ${ }^{23-26}$ Nevertheless, reversible on-off switching of both SCO and SMM in one single crystal triggered by a SC-SC transformation remains unknown.

Undoubtedly, the overwhelming majority of SCO systems are based on octahedral $\mathrm{Fe}^{\mathrm{II} / \mathrm{III}}$ complexes, ${ }^{20}$ while $\mathrm{Co}^{\mathrm{II}}$ compounds are the most studied mononuclear SMM materials including

${ }^{a}$ State Key Laboratory of Coordination Chemistry, Collaborative Innovation Center of Unced Microstructures, School of Chemistry and Chemical Engineering, Nanjing Technology, Wuhan, 430074, China

cJiangsu Key Laboratory for NSLSCS, School of Physical Science and Technology, Nanjing Normal University, Nanjing, 210023, China

Electronic supplementary information (ESI) available: Synthesis, physica measurement, and theoretical calculation details. Crystal data in CIF format and additional figures. CCDC 1816022-1816026 and 1840937. For ESI and crystallographic data in CIF or other electronic format see DOI: $10.1039 / \mathrm{c} 8 \mathrm{sc} 02774 \mathrm{a}$ 
various coordination numbers (2-8) and molecular symmetries. ${ }^{21}$ To explore the potential of $\mathrm{Co}^{\mathrm{II}}$ complexes for both $\mathrm{SCO}$ and SMM bistabilities, Murugesu and co-workers studied the influence of ligand field on SCO and SMM behaviours in three mononuclear $\mathrm{Co}^{\text {II }}$ complexes based on terpyridine (terpy) ligands by controlling the coordination environment of $\mathrm{Co}^{\mathrm{II}}$ ions, where the SMM behaviour could be observed in the five-coordinate $\mathrm{Co}^{\mathrm{II}}$-terpy complex while the SCO behaviour was observed in the sixcoordinate complex. ${ }^{30}$ Another example reported by Hayami and co-workers on $\left[\mathrm{Co}\left(\mathrm{C}_{16} \text {-terpy }\right)_{2}\right]^{2+}$ showed an unexpected reverse spin transition triggered by a structural phase transition. ${ }^{31}$ However, the possible SMM behaviour based on the reverse HS state was not studied. Importantly, these results revealed that the magnetism of $\mathrm{Co}^{\mathrm{II}}$ ions is highly sensitive to minor variations of the coordination environment and reflect the possibility to realize simultaneous tuning of SCO and SMM behaviours through structural perturbation.

Herein, we demonstrate an unprecedented on-off switching of both SCO and SMM behaviors triggered by a reversible SC-SC transformation during dehydration-rehydration of a $\mathrm{Co}^{\mathrm{II}}$ complex, $\left[\mathrm{Co}^{\mathrm{II}}(\mathrm{L})_{2}\right](\mathrm{DPAS})_{2} \cdot \mathrm{DMF} \cdot 2 \mathrm{H}_{2} \mathrm{O}(\mathbf{1})$, and its dehydrated form $\left[\mathrm{Co}^{\mathrm{II}}(\mathrm{L})_{2}\right](\mathrm{DPAS})_{2} \cdot \mathrm{DMF} \quad\left(2, \quad \mathrm{~L}=4^{\prime}\right.$-(4-bromophenyl)$2,2^{\prime}: 6^{\prime}, 2^{\prime \prime}$-terpyridine and DPAS $^{-}=4$-(phenylamino)benzenesulfonate). Detailed structural analyses revealed that the SC-SC transformation alters the local geometry of the $\mathrm{Co}^{2+}$ center and the supramolecular interactions, which in turn leads to a reversible switching of the SCO behavior. Furthermore, the change of the spin states at low temperature results in the switching of the magnetic anisotropy and also the SMM behavior.

\section{Results and discussion}

Dark red crystals of $\mathbf{1}$ were prepared by slow evaporation of the $\mathrm{DMF} / \mathrm{H}_{2} \mathrm{O}$ solution containing the ligand L, NaDPAS, and $\mathrm{Co}\left(\mathrm{ClO}_{4}\right)_{2} \cdot 6 \mathrm{H}_{2} \mathrm{O}$ (see the details in experimental methods, ESI $\dagger$ ). Thermogravimetric analysis (TGA) of 1 (Fig. S1, ESI $\dagger$ ) revealed two desolvation processes: $c a .3 .0 \%$ weight loss in the $20-80{ }^{\circ} \mathrm{C}$ range and $c a .5 .0 \%$ weight loss in the $250-290{ }^{\circ} \mathrm{C}$ range, corresponding to the removal of two $\mathrm{H}_{2} \mathrm{O}$ molecules (calc. 2.5\%) and one DMF molecule (calc. 5.1\%). Guided by this TGA result, orange crystals of 2 can be prepared by heating $\mathbf{1}$ at $130-180{ }^{\circ} \mathrm{C}$. The color change can be monitored by using the variable-temperature single-crystal UV-Vis spectra (Fig. S2, ESI $\dagger$ ). Interestingly, this dehydration process occurred in a SC$\mathrm{SC}$ fashion when the dark red crystals of 1 were heated at $180^{\circ} \mathrm{C}$ under a dry nitrogen gas flow on the X-ray diffractometer. Upon exposure to air for one day, the orange crystals of 2 return to 1 . This reversible dehydration/rehydration process is fully supported by TGA, elemental analyses, powder X-ray diffraction and magnetic studies of 1, 2 and the rehydrated sample 1-re (Fig. S3 and Table S1, ESI $\dagger$ ). Attempts to further remove the DMF molecules in a SC-SC fashion were not successful.

Single crystal X-ray diffraction analyses were performed on $\mathbf{1}$ at 100,150 and $300 \mathrm{~K}$ and on the in situ generated single crystal of 2 at 450, 300 and $150 \mathrm{~K}$ (see the details in the ESI†). Both compounds crystallized in the triclinic space group $P 1$ at all temperatures measured (Tables S1-S3, ESI $\dagger$ ). Their structures are very similar to each other, except for the two $\mathrm{H}_{2} \mathrm{O}$ molecules in $\mathbf{1}$. The asymmetric units of both $\mathbf{1}$ and 2 contain one Co, two unique $\mathrm{L}$ ligands (denoted as $\mathrm{L}_{\mathrm{A}}$ and $\mathrm{L}_{\mathrm{B}}$ ), two DPAS ${ }^{-}$anions and a lattice DMF molecule (Fig. 1). The $\mathrm{Co}^{\mathrm{II}}$ center is coordinated to six nitrogen atoms from two tridentate ligands $\mathrm{L}_{\mathrm{A}}$ and $\mathrm{L}_{\mathrm{B}}$ in a bis-meridional fashion, resulting in a distorted octahedron. The continuous shape measure (CShM) ${ }^{32}$ values for different symmetries were calculated using SHAPE 2.0 and are listed in Table S4. $\dagger$ For an ideal octahedron, the CShM value is 0 , while more deviation from zero means more distortion. As we can see, the CShM values relative to an ideal octahedron are $3.594(100$ $\mathrm{K}), 3.632(150 \mathrm{~K})$ and $4.365(300 \mathrm{~K})$ for 1 , while they are 4.693, 4.653 and 4.667 for 2 at 150,300 , and $400 \mathrm{~K}$, respectively, suggesting a severely distorted $O_{\mathrm{h}}$ symmetry for both $\mathrm{Co}^{2+}$ ions in 1 and 2. The average $\mathrm{Co}-\mathrm{N}$ bond length decreases smoothly from $2.117(300 \mathrm{~K})$ to $2.078(150 \mathrm{~K})$ and to $2.074 \AA$ (100 K) for $\mathbf{1}$, while it remains almost the same for 2 with 2.118, 2.116 and $2.117 \AA$ at 450,300 and $150 \mathrm{~K}$, respectively. These bond lengths are in accordance with the reported values for structurally similar $\mathrm{Co}^{\mathrm{II}}$ terpy based SCO complexes ${ }^{30,31,33-36}$ and clearly indicate that $\mathbf{1}$ undergoes a spin-crossover from 300 to $100 \mathrm{~K}$, while 2 stays in the HS state between 150 and $450 \mathrm{~K}$.

Variable temperature magnetic susceptibilities of $\mathbf{1}$ and $\mathbf{2}$, measured using both heating and cooling modes (Fig. 2a), confirmed the different suspected behaviors. At $300 \mathrm{~K}$, a $\chi_{\mathrm{M}} T$ of $2.83 \mathrm{~cm}^{3} \mathrm{~mol}^{-1} \mathrm{~K}$ for $\mathbf{1}$ indicates the HS state for a Co${ }^{\text {II }}$ center of $S=3 / 2$ with orbital contribution. Upon cooling, the $\chi_{\mathrm{M}} T$ decreases smoothly down to $0.45 \mathrm{~cm}^{3} \mathrm{~mol}^{-1} \mathrm{~K}$ at $2 \mathrm{~K}$, which is consistent with the reported values for a $\mathrm{LS} \mathrm{Co}^{\mathrm{II}}$ center with $S=$ $1 / 2$ and indicates a complete SCO from $S=3 / 2$ to $1 / 2 .^{35}$ The SCO temperature is estimated to be $T_{1 / 2}=125 \mathrm{~K}$. Upon heating, the $\chi_{\mathrm{M}} T$ curve follows the cooling curve exactly in the temperature range of 2-300 K, suggesting no hysteretic effect, as observed in most $\mathrm{Co}^{\mathrm{II}} \mathrm{SCO}$ materials. ${ }^{35}$ Furthermore, the thermodynamic $\chi_{\mathrm{M}} T$ curve below $300 \mathrm{~K}$ can be simulated by the expression $\left(\ln \left[\left(1-n_{\mathrm{HS}}\right) / n_{\mathrm{HS}}\right]\right)=\left[\Delta H+\Gamma\left(1-2 n_{\mathrm{HS}}\right)\right] / R T-\Delta S / R$ obtained from a regular solution model, ${ }^{37}$ giving $\Delta H=3.12 \mathrm{~kJ} \mathrm{~mol}^{-1}$, $\Delta S=21.56 \mathrm{~J} \mathrm{~K}^{-1} \mathrm{~mol}^{-1}$, and $I=1.86 \mathrm{~kJ} \mathrm{~mol}^{-1}$. These results are

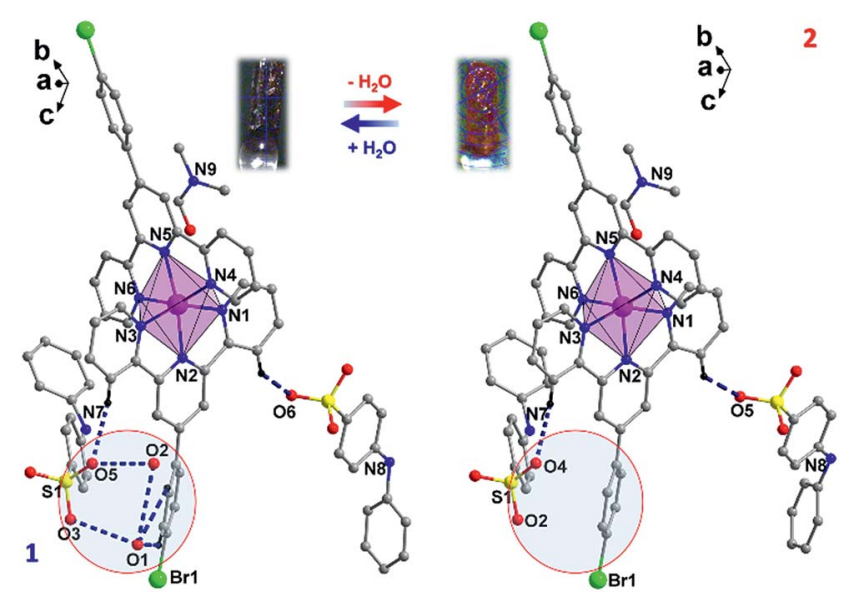

Fig. 1 Asymmetric units of 1 and 2. Hydrogen atoms have been omitted for clarity. The purple dashed lines represent $\mathrm{H}$-bonds. The two water molecules in the circle were removed through dehydration. 

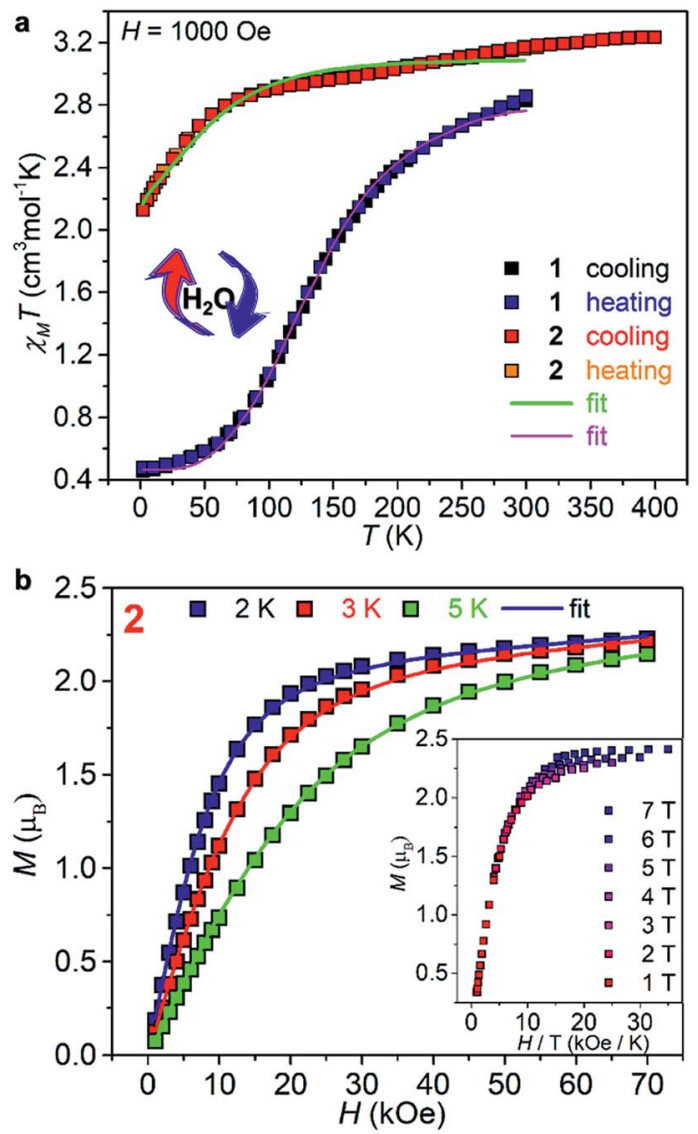

Fig. 2 (a) Susceptibility temperature product $\chi T$ as a function of temperature $(2-400 \mathrm{~K})$ recorded on powder samples of 1 and 2 at an applied field of 1000 Oe. (b) Magnetization as a function of applied magnetic field at 2,3 , and $5 \mathrm{~K}$ for the same sample. The solid lines in (a) and (b) are spin Hamiltonian fits. Inset: reduced magnetization data of 2 collected in the temperature range of $2-10 \mathrm{~K}$ under applied dc fields of $1-7 \mathrm{~T}$.

reasonable compared with other reported $\mathrm{Co}^{\mathrm{II}}$-terpy-based SCO complexes. $^{38}$ The relatively small $\Gamma$ value indicates a small cooperativity associated with the spin crossover. The sample was then kept at $400 \mathrm{~K}$ within a SQUID under a flow of He for two hours to obtain 2, whose magnetic susceptibilities were measured in the further cooling and warming processes. A dramatic magnetic change occurred after dehydration. The $\chi_{\mathrm{M}} T$ decreases from $3.18 \mathrm{~cm}^{3} \mathrm{~mol}^{-1} \mathrm{~K}$ at $400 \mathrm{~K}$ to $1.96 \mathrm{~cm}^{3} \mathrm{~mol}^{-1} \mathrm{~K}$ at $2 \mathrm{~K}$, which is typical for a mononuclear $\mathrm{Co}^{\mathrm{II}}$ complex with a HS anisotropic spin center of $S=3 / 2$, and retains its moment at all temperatures. ${ }^{39,40}$ The final sharp decrease in the $\chi_{\mathrm{M}} T$ curve at low temperature should be mainly due to the intrinsic magnetic anisotropy of the $\mathrm{Co}^{\mathrm{II}}$ ions. $^{39}$

To characterize its magnetic anisotropy, field dependent magnetization $M(H)$ of 2 at 2, 3, and $5 \mathrm{~K}$ was measured (Fig. 2b). The $M$ values increase continuously and reach $2.29,2.28$, and $2.22 \mu_{\mathrm{B}}$ at 70 kOe. An effective spin Hamiltonian $H=D\left[S_{z}{ }^{2}-S(S\right.$ $+1) / 3]+E\left(S_{x}{ }^{2}-S_{y}{ }^{2}\right)+\mu_{\mathrm{B}} B g S(D$ and $E$ are the axial and rhombic zero-field splitting parameters) was employed to fit the $\chi_{M} T(T)$ and $M(H)$ curves simultaneously using the PHI program. ${ }^{41}$ The best fit gave $D=-75.1(8) \mathrm{cm}^{-1}, E=0.35(1) \mathrm{cm}^{-1}, g_{x, y}=2.35(2)$, and $g_{z}=2.68(6)$. The reduced magnetization curves were also measured (Fig. 2b, inset). The resulting isofield curves exhibit significant separation, indicative of a strong magnetic anisotropy of the $\mathrm{Co}^{\mathrm{II}}$ centers.

Furthermore, high-frequency and high-field electron paramagnetic resonance (HF-EPR) experiments were performed on 1 and 2 at $2 \mathrm{~K}$. Absorption EPR signals were obtained because of the transmission mode employed in the HF-EPR spectrometer. The spectrum of 1 shows typical $S=1 / 2$ signals as expected for a LS state of 1 at $2 \mathrm{~K}$ (Fig. S6, ESI $\dagger$ ). Simulations of the data with an $S=1 / 2$ spin Hamiltonian afford $g_{x}=2.22(2), g_{y}=2.16$ (2), and $g_{z}=2.04$ (5) for 1 . As for 2, the experimental spectra of the powder sample were simulated using an $S=3 / 2$ spin Hamiltonian with both positive and negative $D$ values (Fig. 3 a). The simulation $^{42}$ using a negative $D$ value (red line) matches the experimental data better than that using a positive value (blue line) considering the peak positions and shapes, confirming the uniaxial magnetic anisotropy of $2 .{ }^{43}$ It should be noted that as the magnitude of the $D$ value $\left(-75.1 \mathrm{~cm}^{-1}\right.$ from the SQUID measurement) is out of the frequency range in our
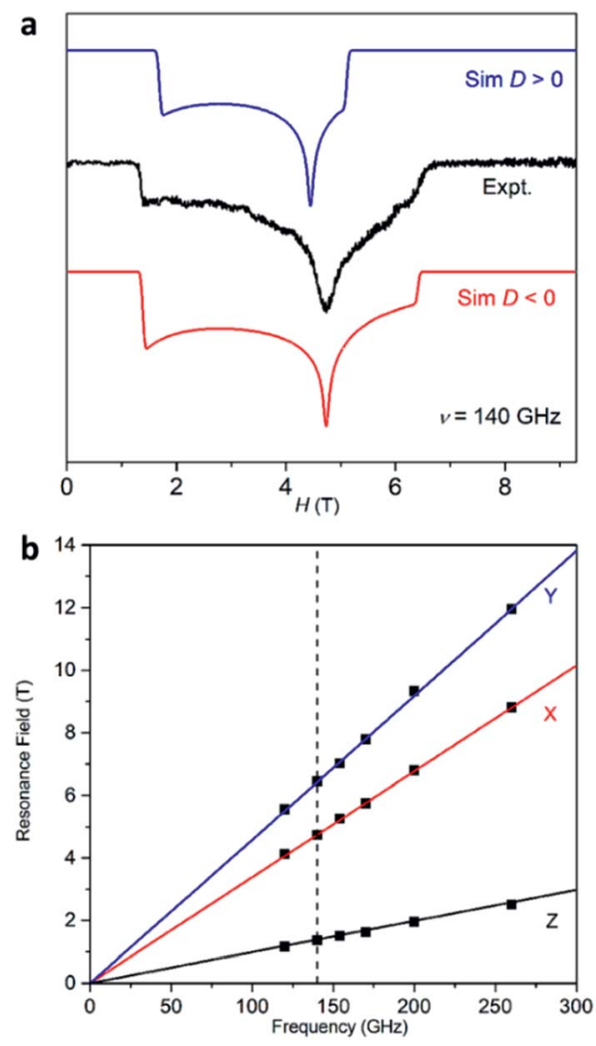

Fig. 3 (a) HF-EPR spectra of 2 with simulations at $140 \mathrm{GHz}$ and $2 \mathrm{~K}$. The blue trace is the spectrum simulated using a positive $D$ value, while the red trace is the spectrum simulated using a negative $D$ value, proving that 2 has a negative $D$ value. The spin Hamiltonian parameters used in the simulations were those obtained from a fit to the 2-D field/ frequency map as in (b). (b) Resonance field vs. microwave frequency of EPR transitions for 2 . The red, blue, and black curves are simulations using the best-fitted spin Hamiltonian parameters with the magnetic field $B$ parallel to the $x, y$, and $z$ axes of the ZFS tensor, respectively. The vertical dashed line represents the frequency $(140 \mathrm{GHz})$ used in (a) at which the spectra were recorded or simulated. 
measurements $\left(260 \mathrm{GHz}, \sim 9 \mathrm{~cm}^{-1}\right)$, no transitions between the Kramers doublets $M_{\mathrm{s}}= \pm 1 / 2$ and $M_{\mathrm{s}}= \pm 3 / 2$ were observed. The HF-EPR spectra were simulated with the $D$ value estimated from SQUID measurements. In addition, a least-square fit to the entire array of HF-EPR resonances extracted at various microwave frequencies gives the best-fit parameters of $g_{x}=2.25(2), g_{y}$ $=2.25(2), g_{z}=2.59(5), D=-75.1(8) \mathrm{cm}^{-1}$ and $E=23.32(3) \mathrm{cm}^{-1}$ (Fig. 3b). Of course, we want to point out that as the simulation of the HF-EPR spectra is only an estimation, the obtained $g$ and $E$ values are different from what we have obtained from the SQUID measurements. Anyway, these results clearly reflect the easy-axis anisotropy of 2 , which is also suggested by the theoretical calculations (vide post).

To gain further insights into their electronic properties, CASPT2 calculations were performed on the basis of X-ray determined geometries of $\mathbf{1}$ and $\mathbf{2}$ (see the details in the ESI $\dagger$ ). The calculated energy levels of the ground and first excited doublets on both the HS states of $\mathbf{1}$ and $\mathbf{2}$ indicate a strong mixing of the two lowest spin quartets (Table S5, ESI $\dagger$ ). Although the energy difference between the lowest two spin-free states (Table S5, ESI $\dagger$ ) for each of complexes 1 and 2 is larger than that between the lowest two spin-orbit states (Table S6, ESI $\dagger$ ), the spin-orbit ground states are all composed of the lowest two spin-free states not only from the ground one (Table S6, ESI†). Thus, we cannot use the zero-field splitting parameters $D$ and $E$ to depict their magnetic anisotropies. The $g$ tensors of the ground and first excited doublets of the $\mathrm{Co}^{\mathrm{II}}$ of $\mathbf{1}$ and 2 were calculated (Table S7, ESI $\dagger$ ). The results reveal a high anisotropy with $g_{z} \gg g_{y}>g_{x}$ in all structures, supporting an easy-axis magnetic anisotropy. Notably, considering that the ground spin-orbit state is not only from the ground spin-free state (Table S6, ESI $\uparrow$ ), the $g$ tensors calculated using CASPT2 were obtained with respect to the effective spin of $\mathrm{Co}^{\mathrm{II}}$ being considered as $1 / 2 .{ }^{43,44}$ However, the $g$ tensors and also the zerofield splitting parameters $D$ and $E$ using HFEPR were obtained by considering the spin of $\mathrm{Co}^{\mathrm{II}}$ as $3 / 2$. We noticed that the calculated orientations of $g_{x}, g_{y}$, and $g_{z}$ on $\mathrm{Co}^{\mathrm{II}}$ of 2 at 150,300 , and $450 \mathrm{~K}$ almost coincide with each other (Fig. S7, ESI $\dagger$ ), agreeing well with its HS state in the whole temperature range.

Dynamic magnetic properties of $\mathbf{1}$ and $\mathbf{2}$ were also investigated. As for 1 , no out-of-phase ac signals $\left(\chi^{\prime \prime}\right)$ were observed under a zero or 1 kOe bias dc field (Fig. S8, ESI $\dagger$ ), consistent with its LS state at low temperatures. For 2 on the other hand, although no $\chi^{\prime \prime}$ signals were observed under a zero dc field, strong ac signals appeared under static dc fields, revealing its slow magnetic relaxation behaviour (Fig. S9, ESI $\dagger$ ). The optimum dc field (1 kOe) to slow down the magnetic relaxation was deduced from the ac measurements under different dc fields (Fig. S9 and S10, inset of Fig. 4b, and Table S8, ESI†े). Detailed frequency- and temperature-dependent ac susceptibility data of 2 were then collected under $H_{\mathrm{dc}}=1$ kOe (Fig. $4 \mathrm{a}$ and S11, ESI $\dagger$ ). From these data, semicircle Cole-Cole plots (Fig. S12, ESI $\dagger$ ) were obtained and fitted to give the values and distribution of the relaxation time ( $\tau$ and $\alpha$, Table S9, ESI $\dagger$ ). ${ }^{45}$ The $\alpha$ values are from 0 to 0.13 , suggesting a narrow distribution of relaxation times. From the fit of the high temperature data in the Arrhenius plot $\left(\ln (\tau)\right.$ vs. $T^{-1}$, Fig. $\left.4 \mathrm{~b}\right)$ with the Arrhenius law
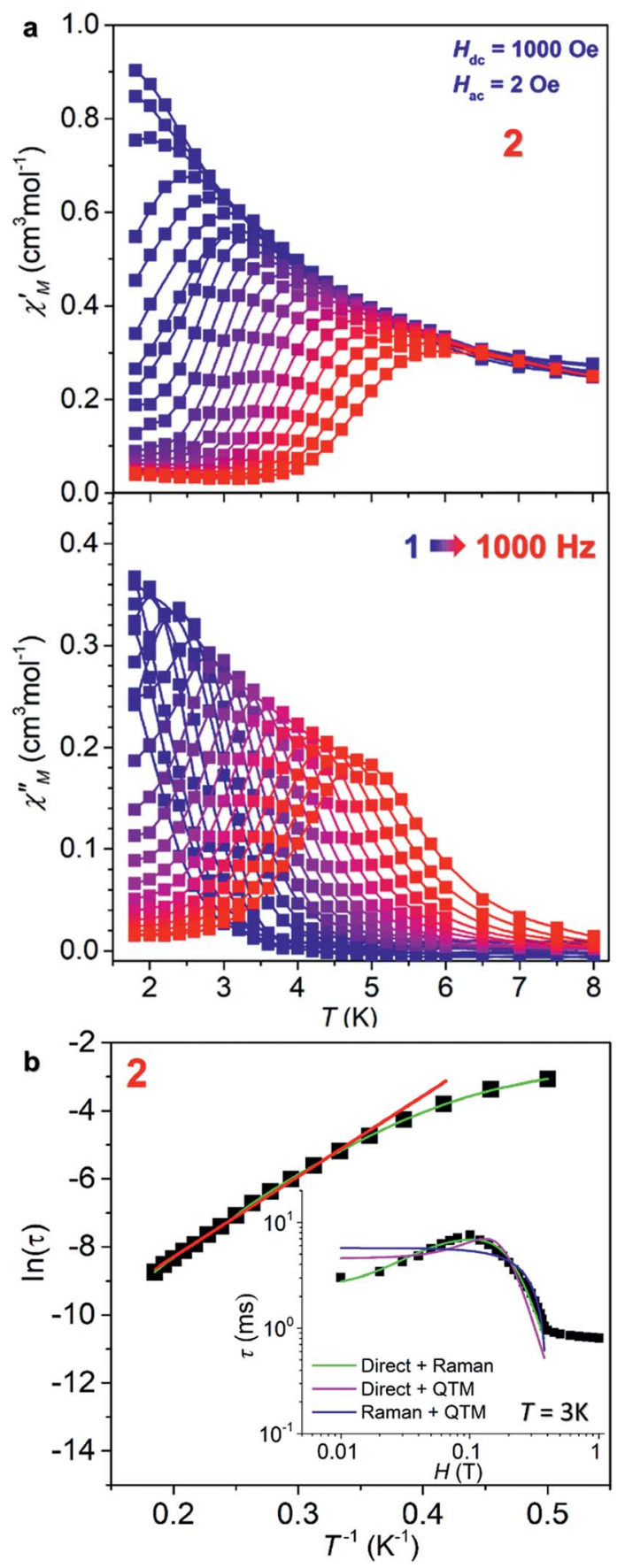

Fig. 4 (a) The in-phase $\left(\chi^{\prime}\right)$ and out-of-phase $\left(\chi^{\prime \prime}\right)$ components of the ac susceptibilities as a function of $T$ of 2 in 1000 Oe dc field at different frequencies $(1-1000 \mathrm{~Hz}$ ). (b) Natural logarithm of the relaxation time In $\tau$ as a function of the inverse temperature $T^{-1}$. The straight red line is a fit of the 12 points at highest temperatures to the Arrhenius law $\ln \tau=$ $\ln \tau_{0}+U_{\text {eff }} / k_{\mathrm{B}} T$. The curved green line is the best fit to the sum of the direct and Raman processes (see ESI + ). Inset: field dependence of the magnetic relaxation times at $3 \mathrm{~K}$ for 2 and its approximation by the different models assuming two magnetic relaxation mechanisms, where only the sum of the direct and Raman processes gives a good fit.

$\tau=\tau_{0} \exp \left(U_{\text {eff }} / k_{\mathrm{B}} T\right)$, the effective energy barrier was estimated to be $U_{\text {eff }}=34.1 \mathrm{~K}\left(23.6 \mathrm{~cm}^{-1}\right)$ with $\tau_{0}=2.1 \times 10^{-7} \mathrm{~s}$. The obtained $U_{\text {eff }}$ is far too small compared with the energy gap estimated 
from the $|2 D|$ value $\left(150 \mathrm{~cm}^{-1}\right)$ and also the calculated energy gap between the ground and excited doublets (Table S7 $\dagger$ ), suggesting that the Orbach relaxation pathway is unlikely for 2. In addition, the slight curvature at low temperature in the Arrhenius plot indicates the existence of multiple relaxation pathways. Detailed analyses support that Raman and direct relaxation mechanisms should dominate in the magnetic relaxation in 2 (see the details in the ESI $\dagger$ ). Notably, magnetic measurements on the rehydration sample of $\mathbf{1}$ and its dehydrated sample confirmed again the reversibility of the dehydration/rehydration process (Fig. S13, ESI†ं).

The above results clearly show that the SC-SC transformation leads to the reversible on-off switching between SCO and SMM (SCO-on/SMM-off (1) $\leftrightarrow$ SCO-off/SMM-on (2)) in one material. Its design principle and structure-property relationship are worth more discussions. The design of this interesting system relies on the unique magnetic properties of the $\mathrm{Co}^{\mathrm{II}}$ ion. On the one hand, the high magnetic anisotropy of the $\mathrm{HS} \mathrm{Co}^{\mathrm{II}}$ ions has led to numerous $\mathrm{Co}^{\mathrm{II}}$-SIMs. ${ }^{39,40}$ On the other hand, $\mathrm{Co}^{\mathrm{II}}$ compounds have also played very important roles in SCO materials. Therefore, by tuning the ligand field of the Co-terpy complexes $\left([\mathrm{Co} \text { (terpy })_{2}\right]^{2+}$ and $\left[\mathrm{Co}\right.$ (terpy) $\left.\mathrm{X}_{2}\right], \mathrm{X}=\mathrm{Cl}^{-}$or $\left.\mathrm{NCS}^{-}\right)$, Murugesu et al. and Hayami et al. have succeeded in the preparation of unique complexes with either SMM or SCO behaviors. ${ }^{30,31}$ Here, we developed another strategy by taking advantage of the sensitivity of the $\mathrm{Co}^{\mathrm{II}} \mathrm{SCO}$ compounds. In fact, since the entropy change of SCO for a $\mathrm{Co}^{\mathrm{II}}$ ion $(S=1 / 2 \leftrightarrow S=3 / 2)$ is much smaller than those for $\mathrm{Fe}^{\mathrm{II} / \mathrm{III}}$ ions, the SCO properties of the $\mathrm{Co}^{\mathrm{II}}$ compounds are more sensitive to small structural changes, as observed in the Co-terpy compounds with long alkyl chains. ${ }^{31}$ This feature offers a good opportunity to achieve dynamic materials with switchable spin states. As the magnetic anisotropy of the $\mathrm{HS} \mathrm{Co}^{\mathrm{II}}$ is usually large, a dynamic material with switching of SCO and SMM behaviours is also anticipated.

As for its structure-property relationship, careful inspection of the structures provides some clues. A range of supramolecular interactions, including the $\mathrm{H}$-bonds between $\mathrm{H}_{2} \mathrm{O}$, DAPS ${ }^{-}$and $\mathrm{L}$ ligands and $\pi-\pi$ interactions between the aromatic rings, exist in 1 (Fig. 5 and Table S10, ESI $\dagger$ ). Connected by the $\mathrm{NH} \cdots \mathrm{O}$ and $\mathrm{OH}^{\cdots} \mathrm{O}$ H-bonds, the DPAS ${ }^{-}$anions and water molecules form 1D ladders along the $a$ axis (Fig. 5a). Interestingly, half of the $\mathrm{L}$ ligands $\left(\mathrm{L}_{\mathrm{A}}\right)$ are locked inside the square windows of the ladders by the $\mathrm{CH} \cdots \mathrm{O}$ hydrogen bonds between the $\mathrm{O}$ atoms from $\mathrm{H}_{2} \mathrm{O}$ and the $\mathrm{SO}_{3}{ }^{-}$and $\mathrm{C}-\mathrm{H}$ groups from $\mathrm{L}_{\mathrm{A}}$ ligands. Furthermore, $\pi-$ $\pi$ interactions between the pyridine rings of $\mathrm{L}_{\mathrm{B}}$ and the benzene rings of the DAPS $^{-}$anions were also found (Fig. 5b). After dehydration, $\mathrm{H}$-bonds involving $\mathrm{H}_{2} \mathrm{O}$ molecules are all removed, which has two direct impacts on the supramolecular interactions. (I) The hydrogen bonded ladders no longer exist and the locking effect of the $\mathrm{L}_{\mathrm{A}}$ ligands is eliminated. (II) The $\pi-\pi$ interactions mentioned above are weakened due to the rotation of the benzene rings of the DAPS ${ }^{-}$anions. Consequently, the $\mathrm{L}$ ligands in $\mathbf{2}$ are much more loosely packed compared to those in 1, which results in a more distorted octahedron of the $\mathrm{Co}^{2+}$ center in $\mathbf{2}$. This is confirmed by a range of parameters, such as the large CShM value of 2 at $300 \mathrm{~K}$ (see above), the larger distortion parameters $\Sigma$ and $\Theta$ of 2 (Table S3, ESI $\dagger$ ), ${ }^{46}$ and the

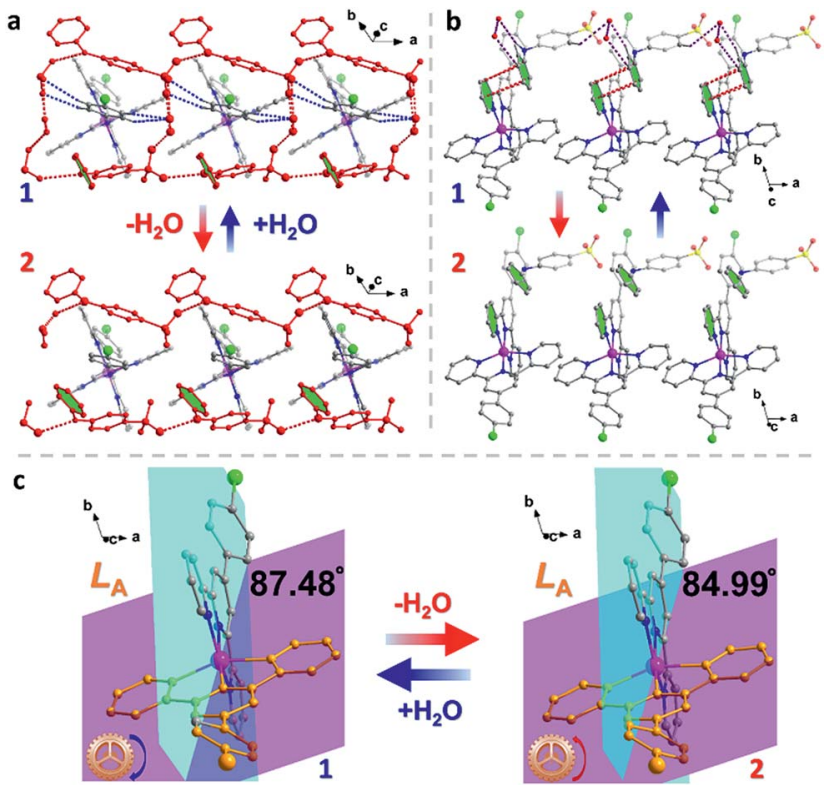

Fig. 5 (a) The DPAS ${ }^{-}$anions connect themselves and interact with water molecules, forming porous 1D ladders along the a axis through a set of hydrogen bonds, which disappear after dehydration in 2. (b) The breaking/formation of $\pi-\pi$ interactions (centroid $\cdots$ centroid distance is $3.65 \AA$ at $300 \mathrm{~K}$ and $3.56 \AA$ at $100 \mathrm{~K}$ ) between the pyridine rings of $L_{B}$ and the benzene rings of the DAPS ${ }^{-}$anions. (c) The rotation of the $L_{A}$ ligand upon the dehydration/rehydration processes in 1 and 2 .

smaller dihedral angle between the least-square planes of the two L ligands $\left(87.48^{\circ}\right.$ in 1 vs. $84.99^{\circ}$ in 2 at $300 \mathrm{~K}$, Fig. 5c). Apparently, the large distortion of the $\mathrm{Co}^{2+}$ octahedron favours the HS state and prevents the SCO from taking place in 2.

\section{Conclusions}

In summary, we demonstrated the achievement of the first example of reversible on-off switching of both the SCO and SMM behaviours in one single material through a crystal-tocrystal transformation during dehydration-rehydration. The magnetic switching occurred in a non-porous mononuclear cobalt(II) complex and is triggered by the modification of the ligand field induced by changes in the supramolecular interactions. These results highlight the importance of the weak supramolecular interactions and suggest an alternative strategy for the construction of switchable materials using SCO materials of high sensitivity and high magnetic anisotropy.

\section{Conflicts of interest}

There are no conflicts to declare.

\section{Acknowledgements}

This work was supported by the National Key R\&D Program of China (2018YFA0306002), NSFC (21522103, 21471077, 91622110, 21701046, and 11774178) and the NSF of Jiangsu Province (BK20150017 and BK20151542). We also thank Prof. Mohamedally Kurmoo for the valuable discussions. 


\section{Notes and references}

1 O. Sato, Nat. Chem., 2016, 8, 644-656.

2 M. Magott, O. Stefańczyk, B. Sieklucka and D. Pinkowicz, Angew. Chem., Int. Ed., 2017, 129, 13468-13472.

3 M. Reczyński, S. Chorazy, B. Nowicka, B. Sieklucka and S. Ohkoshi, Inorg. Chem., 2017, 56, 179-185.

4 M.-H. Zeng, Z. Yin, Y.-X. Tan, W.-X. Zhang, Y.-P. He and M. Kurmoo, J. Am. Chem. Soc., 2014, 136, 4680-4688.

5 M. Wriedt, A. A. Yakovenko, G. J. Halder, A. V. Prosvirin, K. R. Dunbar and H.-C. Zhou, J. Am. Chem. Soc., 2013, 135, 4040-4050.

6 H.-Y. Wang, J.-Y. Ge, C. Hua, C.-Q. Jiao, Y. Wu, C. F. Leong, D. M. D. Alessandro, T. Liu and J.-L. Zuo, Angew. Chem., Int. Ed., 2017, 56, 5465.

7 W.-B. Chen, J.-D. Leng, Z.-Z. Wang, Y.-C. Chen, Y. Miao, M.-L. Tong and W. Dong, Chem. Commun., 2017, 53, 78207823.

8 S. Rodríguez-Jiménez, H. L. C. Feltham and S. Brooker, Angew. Chem., Int. Ed., 2016, 55, 15067-15071.

9 J. S. Costa, S. Rodríguez-Jiménez, G. A. Craig, B. Barth, C. M. Beavers, S. J. Teat and G. Aromí, J. Am. Chem. Soc., 2014, 136, 3869-3874.

10 J. E. Clements, J. R. Price, S. M. Neville and C. J. Kepert, Angew. Chem., Int. Ed., 2014, 53, 10164-10168.

11 D.-Q. Wu, D. Shao, X.-Q. Wei, F.-X. Shen, L. Shi, D. Kempe, Y.-Z. Zhang, K. R. Dunbar and X.-Y. Wang, J. Am. Chem. Soc., 2017, 139, 11714-11717.

12 J. Vallejo, E. Pardo, M. Viciano-Chumillas, I. Castro, P. Amoros, M. Deniz, C. Ruiz-Pérez, C. Yuste-Vivas, J. Krzystek, M. Julve, F. Lloret and J. Cano, Chem. Sci., 2017, 8, 3694-3702.

13 X.-J. Zhang, V. Vieru, X.-W. Feng, J.-L. Liu, Z.-J. Zhang, B. Na, W. Shi, B.-W. Wang, A. K. Powell, L. F. Chibotaru, S. Gao, P. Cheng and J. R. Long, Angew. Chem., Int. Ed., 2015, 54, 9861-9865.

14 S. Fortier, J. J. L. Roy, C.-H. Chen, V. Vieru, M. Murugesu, L. F. Chibotaru, D. J. Mindiola and K. G. Caulton, J. Am. Chem. Soc., 2013, 135, 14670-14678.

15 J.-L. Liu, Y.-C. Chen, Y.-Z. Zheng, W.-Q. Lin, L. Ungur, W. Wernsdorfer, L. F. Chibotaru and M.-L. Tong, Chem. Sci., 2013, 4, 3310-3316.

16 K. Suzuki, R. Sato and N. Mizuno, Chem. Sci., 2013, 4, 596-600. 17 Q. Zhou, F. Yang, B. Xin, G. Zeng, X. Zhou, K. Liu, D. Ma, G. Li, Z. Shi and S. Feng, Chem. Commun., 2013, 49, 82448246.

18 M. Fujimoto, The Physics of Structural Phase Transitions, Springer, New York, 2003.

19 G. K. Kolea and J. J. Vittal, Chem. Soc. Rev., 2013, 42, 17551775.

20 M. A. Halcrow, Spin Crossover Materials: Properties and Applications, John Wiley \& Sons Ltd., New York, 2013.

21 G. A. Craig and M. Murrie, Chem. Soc. Rev., 2015, 44, 21352147.

22 D. N. Woodruff, R. E. P. Winpenny and R. A. Layfield, Chem. Rev., 2013, 113, 5110-5148.
23 A. Urtizberea and O. Roubeau, Chem. Sci., 2017, 8, 22902295.

24 X. Feng, C. Mathonière, I.-R. Jeon, M. Rouzières, A. Ozarowski, M. L. Aubrey, M. I. Gonzalez, R. Clérac and J. R. Long, J. Am. Chem. Soc., 2013, 135, 15880-15884.

25 C. Mathonière, H.-J. Lin, D. Siretanu, R. Clérac and J. M. Smith, J. Am. Chem. Soc., 2013, 135, 19083-19086.

26 S. Mossin, B. L. Tran, D. Adhikari, M. Pink, F. W. Heinemann, J. Sutter, R. K. Szilagyi, K. Meyer and D. J. Mindiola, J. Am. Chem. Soc., 2012, 134, 13651-13661.

27 I. A. Gass, S. Tewary, A. Nafady, N. F. Chilton, C. J. Gartshore, M. Asadi, D. W. Lupton, B. Moubaraki, A. M. Bond, J. F. Boas, S.-X. Guo, G. Rajaraman and K. S. Murray, Inorg. Chem., 2013, 52, 7557-7572.

28 H.-H. Cui, J. Wang, X.-T. Chen and Z.-L. Xue, Chem. Commun., 2017, 53, 9304-9307.

29 D. Shao, L.-D. Deng, L. Shi, D.-Q. Wu, X.-Q. Wei, S.-R. Yang and X.-Y. Wang, Eur. J. Inorg. Chem., 2017, 3862-3867.

30 F. Habib, O. R. Luca, V. Vieru, M. Shiddiq, I. Korobkov, S. I. Gorelsky, M. K. Takase, L. F. Chibotaru, S. Hill, R. H. Crabtree and M. Murugesu, Angew. Chem., Int. Ed., 2013, 52, 11290-11293.

31 S. Hayami, Y. Shigeyoshi, M. Akita, K. Inoue, K. Kato, K. Osaka, M. Takata, R. Kawajiri, T. Mitani and Y. Maeda, Angew. Chem., Int. Ed., 2005, 44, 4899-4903.

32 M. Llunell, D. Casanova, J. Cirera, P. Alemany and S. Alvarez, SHAPE, Version 2.1, Universitat de Barcelona, 2013.

33 X. Zhang, Z.-X. Wang, H. Xie, M.-X. Li, T. J. Woods and K. R. Dunbar, Chem. Sci., 2016, 7, 1569-1574.

34 Y. Guo, X.-L. Yang, R.-J. Wei, L.-S. Zheng and J. Tao, Inorg. Chem., 2015, 54, 7670-7672.

35 S. Hayami, Y. Komatsu, T. Shimizu, H. Kamihata and Y. H. Lee, Coord. Chem. Rev., 2011, 255, 1981-1990.

36 A. K. Bar, C. Pichon and J.-P. Sutter, Coord. Chem. Rev., 2016, 308, 346-380.

37 C. P. Slichter and H. G. Drickamer, J. Chem. Phys., 1972, 56, 2142.

38 A. B. Gaspar, M. C. Munoz, V. Niel and J. A. Real, Inorg. Chem., 2001, 40, 9-10.

39 D. Shao, S.-L. Zhang, L. Shi, Y.-Q. Zhang and X.-Y. Wang, Inorg. Chem., 2016, 55, 10859-10869.

40 S. Gómez-Coca, D. Aravena, R. Morales and E. Ruiz, Coord. Chem. Rev., 2015, 289, 379-392.

41 N. F. Chilton, R. P. Anderson, L. D. Turner, A. Soncini and K. S. Murray, J. Comput. Chem., 2013, 34, 1164-1175.

42 Simulations and fitting were performed using SPIN developed by Andrew Ozarowski in the National High Magnetic Field Laboratory, USA.

43 L. Chen, H.-H. Cui, S. E. Stavretis, S. C. Hunter, Y.-Q. Zhang, X.-T. Chen, Y.-C. Sun, Z. Wang, Y. Song, A. A. Podlesnyak, Z.-W. Ouyang and Z.-L. Xue, Inorg. Chem., 2016, 55, 1260312617.

44 L. F. Chibotaru, L. Ungur, C. Aronica, H. Elmoll, G. Pilet and D. Luneau, J. Am. Chem. Soc., 2008, 130, 12445-12455.

45 K. S. Cole and R. H. Cole, J. Chem. Phys., 1941, 9, 341-351. 46 J. K. McCusker, A. L. Rheingold and D. N. Hendrickson, Inorg. Chem., 1996, 35, 2100-2112. 